\title{
Criminologist in the company a pilot crime prevention
}

\begin{abstract}
The author concludes with the virtue that shows the legal obligation that the company has to adopt and implement within it a model of prevention appropriate cons us particularly situation, containing adequate monitoring and measures control to prevent the aforementioned crimes or to significantly reduces the risk of his commission; which constitutes the introduction of a new paradigm of criminological prevention in the country at the level of the business organization.
\end{abstract}

Keywords: criminology, criminological policy, prevention, prevention program, disclaimer
Volume 6 Issue 5 - 2018

\section{Gino Rios Patio}

Director of the Institute of Legal Research, University of San Martin de Porres, Lima, Peru

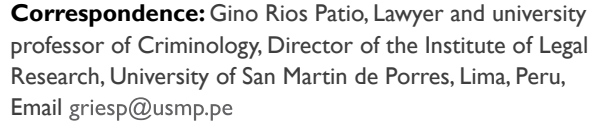

Correspondence: Gino Rios Patio, Lawyer and university professor of Criminology, Director of the Institute of Legal Research, University of San Martin de Porres, Lima, Peru, Email griesp@usmp.pe

Received: June 18, 2018 | Published: November 19, 2018

\section{Introduction}

Crime is -according to precise definition criminology-inter subjective conflict of interest involved in the violence factor that grows exponentially and causing damage to the parties involved and third parties. There are-without a doubt-in this definition, a human component -would best staff-and a social element, which shows the individual and social nature of the crime, under which this conflict phenomenon violent and problematic affects people and society as a whole, so it deserves the attention of every individual, the community and the state. Given the peculiar characteristics of the crime indicated above-to your multicausal and multifactorial nature as well as its ubiquity and its unquenchable nature add-It is not possible to neutralize, control, reduce or less prevent it through the exercise of punitive power, but only through the criminological scientific knowledge, which precisely allows early detection of causes, factors, conditions and criminogenic stimuli, with a view to preventing crime. In that sense, criminology as a holistic social science, studying the causes of crime, analyzes the offender, appreciates the victim and evaluates social control, in order to provide objective and verifiable scientific information to help design policy criminology to advocate effectively achieving the aforementioned preventive purposes and positive intervention actions necessary. The human person-only being with consciousness, will and freedom-It is offending agent par excellence; however, the criminal doctrine-although not peacefullyHe considers that legal person may also commit a criminal offense. It is not the subject of this article, we discuss the reasons for and against the criminal liability of the legal person, just that Act No. 30424-modified Leg. No. 1352-provides that a legal person can have administrative and criminal responsibility for the offenses of bribery active transnational, money laundering, illegal mining, organized crime and collaboration with terrorism and, consequently, deserve severe penalties in these areas, for it is justified-from the standpoint of theoretical and practice-analysis of the new legal requirement that companies have an effective crime prevention program so they can absolve themselves of responsibility. In addition, the social usefulness of the study that this article describes is undeniable, as being a legal obligation very new, it is necessary to disseminate its meaning and scope, in order not only to meet the standard but, above all, to learn about the implementation and characteristics of the compliance program as work product criminologist in the company.
Since ancient times; founders, managers and employees of a private partnership or company, have created and/or used the organization of an entity to commit or facilitate crimes. Are asaz known cases of the retinues of Outlaws of the Middle Ages, companies of mercenaries and condottieri of the Renaissance, the secret brotherhoods of the eighteenth century, the Neapolitan Camorra, the Sicilian Mafia, the cosa Nostra, the gang, the band and up modern criminal organization, transnational in nature. Currently-for reasons having to do with the social, cultural, economic and political change-the causes, factors, conditions and incentives to shift behaviour toward crime possibilities have multiplied and worsened in dañosidad, as in the case of economic crime, environmental crime, organized crime and white-collar crime called. This problem of crime economic or corporate power, has amplified the world and its evolution has meant a mutation of the organizational structure and as effectively multiplying its power, manifested in their criminal actions a real challenge to the national authority. Are varied factors and conditions that have made possible the growth of transnational organized crime that in some of its forms, perpetrated by companies, such as the giddiness and immense possibilities of international transport, which along with other economic factors and they have increased financial flows of legal goods as well as illegal; the operation of trade and production globally; and the vast network of international connections. This postmodern factual situation has demanded the adoption of measures of institutionalized prevention, aimed at minimizing the occurrence or eliminate the risk of crimes committed through the organization of a company, such as the obligation to implement a corporate prevention, which is the result of the work of the criminologist, as argued in this article, which is proposed in chapter show the basics of criminology and criminological policy to spread in business virtues and advantages of this social science regarding the right criminal, giving it greater range and efficiency, so that they are not confused with criminalities and auditing; analyzing and evaluating the second chapter the meaning, scope, conditions, requirements and compliance program effectiveness; exhibit in the third chapter the importance, usefulness and urgency of the situation facing the current unseen crime, criminologist work in a company; and finally arrive at the conclusions involving the introduction of this new criminological preventive measure. 


\section{Criminology and criminological policy Criminology}

Must place the concept study object and purpose of this social science in our country, it is little known and therefore confused with criminology and criminal law. Indeed, criminology is a comprehensive, holistic and multidisciplinary social science longstanding; it is because human science is under study, method and verifiable knowledge. The first criminologists were demonologists of the middle Ages, priests and theologians, first Dominicans and then Jesuits in the service of the Holy Inquisition; certainly, at that time, criminology still did not have a scientific, then they went physicians, Italian and French, who endowed positivist scientism to the discipline of knowledge. Later, the lawyers of the age of Enlightenment, who embraced rationalism and liberalism, introduced criminal guarantees to improve the old regime, which obviously was criticized for his boundless cruelty in punishment of crime. Then, sociologists, notably American, British and European, inaugurated the modern phase of criminology, known as criminology deviation being here that the so-called criminology white collar arises, thanks to the contribution of Edwin Sutherland, who showed what existed and no one wanted to see, that crime also exists in the company, industry, professional law and the state, not only in the factory and slum; and that the criminal may also be the man of high social class, high-level education, solid economy, not only the needy citizens, uneducated, unemployed and low class. Contemporaneously, are criminologists, scientists specifically trained in this discipline, or second specialization or other professional who cultivate and develop academically those responsible for the analysis of the criminal matter, determination of the aetiology of crime, the selection of means and methods of positive intervention in the offender and the victim, and the design of public policy measures to adopt the prevention and control of crime. The object of study of criminology is composed of four large fields or areas such as: crime, criminal, victim and social control, each of these objects of study defined according to the time and criminological school. Currently, for example, the concept of crime we have given above differs from the historically unprecedented, who considered him an evil act, itself a being possessed; an abnormal action arising from a monster or be pathological; the breach of the criminal law; deviant behaviour and contrary learned the system and the dominant values; or an act of political rebellion of a person against the system.

Thus, the criminal is no longer a man possessed, abnormal, monster, deviant or rebellious, but equal to others who decides freely commit certain conduct person to whom the power attributed a negative quality, it is not part of ontologically or that it is not inherent, but a social construct. Similarly, the victim is not only the person suffering damage from criminal behaviour, but fundamentally the eternal forgotten the criminal justice system, which is never compensated nor redressed and that the State expropriates the conflict and acute pain impairment suffered itself of the criminal action. Finally, social control is not coercive and punitive exercise exercised by the State formally or which vertical and militarized way it unfolds through social institutions, but pre- and positive intervention at a structural level and not cyclical must instrumentalism the state. As it is possible to understand at this point, criminology differs from criminal law and criminology. It differs from the first in that this is empirical and study reality, while this is based on an abstract regulations containing factual assumptions and pains to point out what ought to be will never be Instead criminology studies what is the disruptive behaviour of individuals to know their causes and prevention. Moreover, criminalities is not a science but a set of techniques from different natural sciences, which assist in an investigation to determine the who, what, how, when, where, why and for what behaviour perpetrated criminal, obviously after it occurred and then also punishable under criminal law, while criminology finds, establishes and checks the causes of crime, understood as the set of crimes in certain space and time, no mobile or motives, and others situational circumstances, but what should the existence of different kinds of crimes and what their aetiology, course before they occur, so it is preventive rather than reactive. Naturally, the purpose of criminology also depends on the respective historical phase in which it develops. Today, criminology criminological has a political purpose, supplying valid and testable scientific information regarding the aetiology of crime to serve the design of public policies for prevention, reduction, control and punishment of the crime. Historically, although it was political, because all science should be as long as is done to solve common problems of man in society, its purpose was prophylactic and correctionalism.

\section{Criminological policy}

In principle, it should explain why the author prefers to use the term policy criminological and criminal policy not. According fully with Perez, criminological policy means national strategy to prevent and control crime; while the criminal policy suggests the idea of tactics and planning's of criminals in their activities, therefore the term refers to political decision-making a group in power (can be factual) that all members of a group apply such as: the institutional policy of a private business organization, so by extension it can be confused by decisions made by criminal organizations operating in economic crime; by state bodies that meet higher directives to operate in the crime of power; and overall crime established forms of human elements operating internationally recruited and covert to co-opt with government officials in an environment of corruption operations. The use of the term criminological policy, also serves Perez judgment, it also shares the author to distinguish this functional and rational application, finalist of criminology, with the term of criminal prevention, because it is a term overcome this, since it corresponds to schools: cynical, sociological and eclectic traditional criminology. It also serves to differentiate the term social reaction, pointing to the answers, i.e., the reactions of the state against the deviation, which also has been overcome because the theories of the new criminology, related to the deviation, based on social consensus were refuted by the theory of social conflict, so that the concept of misuse could not be said for a given and a reference unanimous. David Matza even said not without irony: what is so wide that a helpless steals? If you're personal situation determines to perform that action so that it can survive both he and his family. From there, the socio-political criminology approach which would mark the beginning of a Copernican revolution in the art from the following thought would occur: the social reaction produces deviation that is crime and criminal. Before it had argued that social deviance produced social reaction, as we jotted down at the beginning of this paragraph. In other words Conflict al citizens create a conflict or a troubled society structurally generates conflicting citizens?

Thus, criminological policy is a comprehensive state policy no sector which brings together the knowledge, techniques, methods, means, resources, tools and regulations to prevent, reduce, control and punish crime in a reasonable, non-arbitrary, unfair, unreasonable 
or disproportionately neither selective nor discriminatory, as befits a constitutional state, social and democratic rule of law. It is often confused with criminal policy, but this is just the exercise of punitive power through the criminal justice system (ius puniendi), Which includes the regulation and operation of the coercive apparatus of the state, which currently presents the characteristics: symbolism, hiperpunitivismo, the over criminalization, illegitimacy, illegality and perversity, as noted Zaffaroni $\mathrm{E}^{1}$ according to Borja $\mathrm{E}^{2}$ criminological policy is the externalization of a state policy that establishes the approach to address and treat the criminal phenomenon, contains not only criminal, but a cross range of measures, mainly economic, social, labour, educational, cultural, urban, health, among others. As an aspect of general policy, each state has a different way of approaching criminal matter, evidently in totalitarian states those in which there is respect for human rights. Criminological policy consider crime as a subversive behaviour, an attitude of disobedience and disrespect of the rules and directives of the government, so only think of exterminating at any cost, because the individual does not count and is subordinate to the state and controlled at all times by the apparatus of power. Are intended to prevent through fear of coercion, this criminological policy is prophylactic. Pérez $\mathrm{A}^{3}$ recognizes this regard, certain political criminology schools, which correspond to respective criminology, such as social defence corresponding to the clinical, psychological and sociological criminology traditional schools; its purpose is to defend the society of criminals, which aims to prevent, protect and reintegrate criminals into society, is manipulating genetic material, sublimating instinctual drives that affect the psyche; and reforming cultural factors, respectively identification.

The same author Pérez Alvaro ${ }^{3}$ also notes the school of alternative criminal policy, corresponding to an approach critical criminology holding the need to transform the structures of society and implement decriminalization of non-serious behaviour, criminal deflation to reduce selfishness and criminal inflation, avoid labelling and stigmatization to reduce crime and decriminalization to eliminate the indiscriminate use and reduce violence in the execution of the sentence to eliminate the disastrous consequence of the deprivation of liberty. Advocates a new process of criminalization, which also corresponds to the critical criminology, to penalize conduct affecting the rights and legal interests of the majority; desprisionizacion process, because the jail does not solve the underlying conflict in the crime; the alternative use of law, to interpret the sociological and anthropological law, and transcending the merely normative legal and overcoming the departure from the norm of reality. School criminological pessimism is also, according to Perez ${ }^{3}$ another way of doing, facing the criminal matter sponsoring the penal abolitionism and replace horizontal measures based on dialogue, harmony and solidarity, to treat deviant behaviour as problematic situations and privatize social conflicts within, as it is the criminal justice system that creates and manufactures criminal crimes. In a democratic state, unlike a totalitarian state, It characterized by respect for the rights and freedoms the crime is considered an inevitable factor, but necessary and useful in social organization, as Emile Durkheim argues, quoted by Tonkonoff S. ${ }^{4}$ Here, according to the position assumed by each criminological school position, the cause of crime may be biological, psychological, social, cultural, economic or political, but in any case, crime rationally be prevented and positive interventions public, as well as a contraction of the penal system policies because what prevails is the human person as transcendent purpose and not as an instrumental means of achieving security.
It is easy to understand when a State is not totalitarian, and is only formally democratic, noting the execution of an erratic criminological policy, as most of the time shows that attempt measures of fundamental rights of the human person, as in the case of creation of new crimes: tougher penalties, elimination or reduction of benefits for certain crimes, denaturation of criminal red-handed, overuse of pre-trial detention, disrespect state (presumed) innocent, investment indubio pro processing, among others. The reason for this madness in which hypertrophy of the penal system is given, is none other than the mistaken claim to achieve high levels of citizen security regardless of the cost in terms of freedom and fundamental rights. Indeed, in Peru, where there is a formal democracy, nonmaterial $\square$ the penal system is regulated and operates with the characteristics indicated by Zaffaroni $\mathrm{E}^{1}$ which makes the exercise of punitive power is selective and discriminatory to the detriment of the most deprived social classes; It has become a symbolic criminal law, i.e. criminal law as Diez J (2002) less oriented to the care and protection of the legal, that does not produce changes in behaviour states; and more oriented effects and political consequences, such as the need for action, which shows a function of illusion and deception, it does not fulfill the purpose of a criminological policy and on the other hand, undermines public confidence in the administration of criminal justice, such as the myth of the resocialization and rehabilitation of the criminal; the myth of claim and compensation of the victim; the myth that the criminal law is equal for all; and the myth of the severity of punishment for crime reduction, among others.

\section{The model of prevention program or compliance}

\section{The newest legal obligation in Peru: nature and scope}

On April 21, 2016, in the official gazette El Peruano, the No. 30424 Act, which regulates the administrative liability of legal persons for the offense of active bribery transnational later on January 7, 2017, was published changed by Leg. No.1352 which expanded the scope of responsibility of the legal entity to include crimes of generic and specific bribery, illegal mining, organized crime, money laundering and terrorist financing within the set of crimes that could lead to the autonomous responsibility of the legal person. The entry into force of the standard, has been postponed until January 1, 2018, it must be regulated before that date, in order to establish and clarify the elements needed to implement and monitor the effective operation of the business model Prevention under which the organization may be exempted from liability, obviously if it was implemented before the commission of the crimes. It should be noted that, although the law denominated as administrative responsibility one that can have a company in carrying out the crimes listed above. It is actually a criminal liability that the legislature did not intend to call by name in order not to label and stigmatize the company, as with natural person who is charged and test its responsibility in the commission of unlawful, so that not only by the fact that it is a criminal judge as the law itself says which he will sentence determining the accreditation of corporate responsibility in the perpetration of the crime, but the very foundation of the attribution of serious social debit tried in a criminal court independently and not subject to that from the behaviour of its owner, officer or official, is that indeed is a criminal liability that may end the existence of the business organization through the measure (penalty) dissolution under the law. The law seeks to penalize not only administratively sanctioning the conduct of a company that 
lacks good corporate practices and organizational culture, ethics, and puts your organization at the service of the commission of the crimes mentioned above or exposes irresponsibly lacking programs control and prevention, clearly violating his order and social responsibility as a production unit of legal goods and services to contribute to the development and security of society and the country.

The new legal provision now reaches not only to companies but also to non-governmental organizations, civil associations are nonprofit. It has broadened the original scope, which was limited to associations, foundations and non-registered committees, irregular societies, autonomous entities that manage assets, private companies and the Peruvian government or semi-public companies. Reliever matter that according to law the change of name, corporate name, social reorganization, transformation, split, merger, dissolution, liquidation or any act that may affect the legal status of the entity, does not prevent judicial attribution of liability to the company. Among the modifications introduced by Leg. No. 1352, draws attention to the provisions of para. 3art. 2, according to which: In the case of a merger or division, the entity absorbent:

I. Only may be sanctioned with a fine, calculated taking into account the rules set out in Articles 5 or 7, as appropriate, depending the transferred assets, provided that the offense was committed before the merger or division, unless the legal entities involved have used these forms of corporate reorganization in order to avoid possible administrative liability of the merged or spun-off entity, in which if this assumption does not operate; and,

II. Does not incur administrative responsibility when made adequate due diligence prior to the merger or division.

This arrangement allows the limitation analyze making authority for certain cases as referred to in determining the penalty e.g. fine on the acquiring company rather than disqualification, Of which it is not possible to understand the visible reason. On the other hand, it is noteworthy in that same legal provision; however, that the acquiring company incurs no administrative responsibility when you have made a proper due diligence prior to the merger or demerger, which emphasizes the need to implement the model of prevention to avoid the judicial declaration of responsibility, contributing, without a doubt to build a corporate culture respectful of the law and a suitable climate for maintaining ethical values with the greatest scrupulousness you must precautionary company in developing its activities.

\section{Attributing criminal liability to the company autonomy responsibilities}

The law has established that legal persons are administratively responsible for the crimes described above, when they are committed on their behalf or on behalf of them and their direct or indirect benefit, by:

I. Its partners, directors, managers fact or law, legal representatives or agents of the corporation or its affiliates or subsidiaries,

II. The natural person who, being under the authority and control of the persons mentioned in the preceding paragraph, has committed the crime under his command or under their authorization and

III. The natural person referred to in the preceding section, when the offense has been possible because the persons mentioned in paragraph a, have breached their duties of supervision, monitoring and control over the activity entrusted, in view of the specific situation of the case.

In addition, legal entities having the status of parent be responsible and sanctioned, if natural persons of its affiliates or subsidiaries who engage in any conduct specified in para. Previous they have acted under his orders, authorization or consent. Legal entities are not liable in cases where natural persons indicated above, had committed the offenses that the law refers solely for their own benefit or for a third party other than the legal person. As you can see, the responsibility is no longer solely the proper scope of the largest business organization, but extends to its related companies, which tells of the recognized need for breadth and effectiveness of a model of institutional prevention and powerful in the organization, as well as the assumption of good corporate practices, ranging from a jealous recruitment to timely and accurate system of internal controls to ensure a suitable decisionexempt decisions criminal risks, the law opts for by establish indirect responsibility assumed by who chooses to perform other functions. Moreover, the law states that the administrative responsibility of the legal person is independent of the criminal responsibility of the individual, so the causes of termination of criminal proceedings against the natural person do not enervate the administrative responsibility of legal persons.

\section{Criminological and criminal defence in this new scenario}

In referring to the defence against a court complaint should always be from an ethical basis, that is, defend the truth, without inventing facts and evidence alone; without lie or confuse or disrupt the facts. The law, which has a three-dimensional composition: factual, normative and axiological, is synthesized in facts, evidence and rules, this insuperable old formula, evidence for the purpose of prosecution, which is the search for truth to resolve an inter conflict interests justice to contribute to social peace, in the case of criminal behaviour of legal persons would teleological commitment to the community in which they operate, subject to profit in the case of companies I insist it is their element, but not to be confused with the prioritization of interest to maximize profits through crime. But both the facts and the evidence and rules are subject to systematic and formal interpretation, precisely so that the result of this interpretation permits reasonable application of the rule to the specific case, thus overcoming the underlying conflict. In that sense, the facts must be presented categorically and emphatically., But should be tested by appropriate means of whose subsequent discussion arises an assessment that supports the accuracy of the facts shown, this will lead eventually to the implementation of the relevant rules previous interpretation from the various existing hermeneutical methods. Doctrine and jurisprudence can assist and complement this technical task of the defence, but it should be noted that the doctrine consists of theories that have the same epistemological value and recurrence by one, it depends on the level of consensus achieved but still it is not decisive; and jurisprudence, which is the jurisprudential precedent decision in a similar case, although it can display the current orientation of the supreme court, has the limitation of the principle of legality and the principle of the prohibition of analogy in criminal matters. 


\section{Exculpatory circumstances of liability of the legal person}

The new regulation provides that the legal person is exempt from responsibility for the commission of the offenses provided, if adopted and implemented in your organization, prior to the crime, a model of appropriate prevention nature, risks, needs and characteristics consisting of surveillance measures and good control to prevent the above offenses or to significantly reduce the risk of their commission. Such prevention model must have the following minimum elements:

I. A prevention officer appointed by the highest governing body of the legal person or the person acting as appropriate, who should exercise their function independently. In the case of micro, small and medium enterprises, the role of prevention officer may be assumed directly by the board,

II. The identification, assessment and mitigation of risks to prevent the commission of the offenses covered by the legal person,

III. Implementation of complaints procedures,

IV. Dissemination and regular training of prevention model,

\section{Evaluation and continuous monitoring of prevention model.}

In the case of micro, small and medium enterprises, the prevention model will be limited to its nature and characteristics, and should only have one of the aforementioned minimum elements. In the case of State enterprises or mixed economy companies, the prevention model is exercised without prejudice to the powers and powers that correspond to organs of institutional control as all conform antes bodies of the National Control System. the responsibility of the legal person is also excluded, as partners, principals, administrators of fact or law, legal representatives or agents of the corporation or its affiliates or subsidiaries, committed the offense eluding fraudulently the prevention model properly It implemented also in cases where individuals had committed the offenses provided solely for their own benefit or for a third party other than the legal person. From the foregoing, it follows that what the law punishes is corporate criminal or legal person responsibility for failing to put in place a prevention program internal risk to commit crimes she says, stating supervision and effectiveness. Unpredictable risks are not tackled by any prevention program, so it is illogical to punish a company for acts for which no legal or factual to avoid possibility, even having adopted the appropriate rules to avert the danger involved in the development of its activities, which are risks, needs and characteristics of their business characteristics. So far, then, you can display generically when and how a company can defend itself against a criminal complaint under the law. Therefore, the defence should be focused on:

I. Timely and effective implementation of a program of criminological prevention,

II. The accreditation of the offender used fraudulent manoeuvres to circumvent controls program running, and

III. Demonstration that the offender's own benefit or for a third party other than the legal person.

Where paragraph (i) is the fact; paragraphs (ii) and (iii) are the tests; and rules are made specifically by Law No. 30424 and D. Leg. No. 1352 and more broadly by constitutional principles and postulates and criminal provisions of national law. It should be noted that the creation and design of a program of crime prevention since it is designed to eliminate foreseeable risks in the overall operations of a company necessarily it requires a specific, particular, and own ad hoc configuration, business, to assess the economic, financial, administrative, physical, operational, technological and other human resources, which runs its business activity and fulfils its purpose. This appears clearly the criminological approach no criminal. Therefore it is studied the peculiar reality of the company in order to determine possible causes, factors, conditions and reasons that could arise for the perpetration of illicit stipulated by law. Since the penal approach is intended to act ex post facto, that is, after the events occurred incriminated, it is not possible to foresee, but to act in defence of the threat of a penalty, which can be fatal for the company, defence case it could prove ineffective precisely because of the facts and evidence, as we said, must not be falsified or altered. Instead, criminological perspective ex ante operates with absolute prevention and thus should and can cope better way to what happens later, that difference makes the advantage in a legal defence.

\section{The sanctions imposed by the judge}

In the cases covered by the new regulations, the legal person shall be liable for any of the following measures:

Penalty fee not less than twice or greater than six times the profit made or expected to be obtained with the crime. When you cannot determine the amount of the benefit obtained or expected to obtain with the commission of the offenses that the law refers to the value of the fine is established according to the following criteria: a) when the annual income legal person at the time of the crime amounted to 150 UIT, the fine is not less than 10 nor more than 50 UIT, b) when the annual income of the legal person at the time of the crime is greater than 150 ITU less than 1700 , the fine is not less than 50 nor more than 500 ITU. c). When the annual income of the legal person at the time of the crime is greater than 1700 ITU, the fine is not less than 500 nor more than 10000 ITU. The fine must be paid within ten working days of delivery of the judgment that has the quality of accepted or enforceable. At the request of the legal person and when payment of the amount of the fine could endanger its continuation or maintenance of jobs, or when advisable in the public interest, the judge authorizes the payment be made in monthly instalments within a limit not exceeding 36 months. If the legal person fails to comply with the payment of the fine imposed, it can be run on its assets or converted prior injunction, to the extent ban definitively activities. Disablement, either in the form of:

I. Suspension of social activities for not less than six months nor more than two years; or in the form of

II. Prohibition, temporary — between one and five years — or final, to carry out future activities of the same kind or nature of those whose conduct has been committed, aided or concealed the offense; or

III. To contract with the State final, which will be imposed on a mandatory basis in cases where the offense is committed in the context of a procurement process.

Cancellation of licenses, concessions, fees and other administrative or municipal authorizations, which applies compulsorily when the active transnational bribery offense was intended or linked to licensing or other administrative authorizations. The closure of its premises or establishments on a temporary basis between one and 
five years or definitive. The solution, which will apply only to legal persons that have been set up and operated to promote, facilitate or conceal the crime of transnational bribery active in any case, be applied to other circumstances. This measure does not apply in the case of legal persons of private law and State enterprises or mixed economy companies providing public utility services, whose interruption would cause serious social or economic consequences or serious damage to the community. The new regulation also provides for complementary measures such as the intervention of the legal person found responsible for committing offenses under, where necessary, to safeguard the rights of workers and creditors up for a period of two measures years, it can affect the entire organization or restricted to some of its facilities, sections or business units, the judge must set exactly the content and scope of the intervention and determine the entity in charge of the operation and the time periods this should be entitled to issue reports to follow up the measure, the auditor is entitled to access all facilities and premises of the entity and obtain the information it deems necessary for the performance of their duties, must maintain strict confidentiality of the secret or confidential information of the legal person under responsibility.

\section{Public register of sanctions}

On the other hand, the regulation provides that there will be a computer record held in public by the judiciary where such sanctions for appropriate action, in which the name, class size and duration thereof shall be recorded are noted as well as the detail of the court and date of the final judgment without prejudice to attend parties to public records for the corresponding registration, if applicable. Should legal entities comply with the measure imposed, the judge ex officio or upon request orders his retirement from registration, unless the measure is final.

The judiciary may enter into agreements with the Supervisory Agency for State Procurement (OSCE), among other institutions, to share information recorded in the log. It is about strictly speaking a sort of central registry of convictions and works for convicted individuals, which is considered appropriate to allow access of society to information about which companies have been sanctioned, what is not understood is the special reason which the judiciary can sign agreements with the OSCE and other agencies to share information, if it is public, there is here a good legislative technique. As you can see, it is true criminal penalties similar to those natural persons whose criminal liability imposed is adjudicated, including a record that will act as a central register of convictions. Moreover, the fact that a criminal judge is empowered to impose the results of a trial with all guarantees, leaves no doubt that it is not a criminal and administrative sanction.

\section{Do you publish the defence of the legal person?}

The new legal provision establishes the possibility that the accused company can be assisted by public defence case requires this, although it is consistent with the condition of the accused, it cannot be unaware that the origin of public defence arises the duty of the State to provide free legal technical defence to defendants who lack the resources to do so, because of an issue garantista protection and protection of fundamental rights; so it is not reasonable that the same provision governing when there is the same reason in fact, obviously, usually, a company has more resources than a natural person and address the shortage of state resources, they must prioritized and disbursed in accordance with the principle of necessity. Who will be responsible for exercising this defence that the state could subcontract to third parties? How and why public money could be used to pay fees for a technical defence of a company under investigation for these crimes? It seems that is not successful arrangement.

\section{Aggravating circumstances of the criminal responsibility of the legal person}

Where the legal person is used instrumentally for the commission of offenses to which the law is concerned, that is, when its activity is predominantly unlawful; when it contains within its structure a body, unit, equipment or any other body whose purpose or activity is illegal, assuming responsibility is aggravated. Also, when you have committed any of the offenses covered within five years after the date on which has been imposed by a judgment which one or more measures; also it considered aggravating the effects of increasing measures in up to one half above the legal maximum established.

\section{Extenuating circumstances of the criminal responsibility of the legal person}

When the objective working entity, substantial and decisive in clearing up the offense, even before the start of the intermediate stage; prevents the harmful consequences of the offense; totally or partially repaired the damage; adopts and implements itself after the crime and before the start of the trial, a prevention model; partially credits minimum prevention model elements; makes confession, duly substantiated, of the crime, prior to the formalization of the preliminary investigation; It assumes responsibility dims and has the effect that the judge can reduce certain measures up to one third below the legal minimum established, in the case of temporary measures. Diminished responsibility is not applicable in case of flagrante delicto, irrelevance of admission charges in view of the evidence incorporated in the process, or has been configured recidivism. It is noted that the adoption and implementation of a prevention model that occurred after the crimes, should not serve to lessen the responsibility of the company, for crimes already have occurred and its effects accomplished precisely for violating its legal obligation.

\section{Criteria for sanctions}

The regulation requires the severity of the offense; the economic capacity of the legal person; the extent of damage or danger caused; economic benefit to the offense; the motive for the crime; and since the structure of the legal person occupies the natural person or body that breached the duty control; are the criteria that the judge should follow for determining penalties. It is appreciated that this is a proper relation to the aims.

\section{Suspension of enforcement measures}

According to the regulations, the judge may duly reasoned and exceptionally resolution, the suspension of the implementation of the measures imposed and their purpose for not less than six months nor more than two years, provided that the measure it imposed is below the lower third, in which case the legal person shall impose the following rules:

\section{i. The total reparation and}

ii. The obligation to adopt and implement a prevention model. 
If during the suspension period the entity does not comply with the rules imposed, the judge may, as appropriate:

i. extend the period of suspension half timeframe; in any case the accumulated extension must exceed two years, or

ii. Terminate the ordered suspension.

If the suspension period elapses without the legal person is incorporated into new criminal proceedings and compliance with the rules imposed verified, the judge revokes the penalty imposed and solves the dismissal of the case. It is noted that with the dismissal which is made possible, which has the effect of res judicial, to be annulled the penalty originally imposed and subsequently suspended, the legal person would be legally rehabilitated and could rejoin the economic, financial and trading system without any problem. With the rehabilitated individuals occurs, however, the opposite, they maintain the label and convicted criminal stigma that segregates society.

\section{The procedural requirement to formalize a business research}

The eighth additional and final disposition of Law No. 30424 Act, as amended by Legislative Decree No. 1352, provides that the Superintendence of Securities (SMV), which is under the Ministry of Economy and Finance specialized technical agency, is authorized to issue a technical report quality institutional expertise, which constitutes a procedural requirement to formalize the preliminary investigation for crimes that the law, which will review the implementation and operation of prevention models concerns. The SMV is designed to ensure investor protection, efficiency and transparency of the markets under their supervision, proper price formation and dissemination of all information necessary for such purposes, practical, administrative, economic autonomy, technical and budget; sort is obvious that, according to its organic law, has jurisdiction only for listed companies, but not for associations, foundations and committees not registered, irregular societies, bodies which administer a trust, state enterprises Peruvian or mixed companies and non-governmental organizations (NGOs), which unlisted; so it is not a suitable body to assess the effectiveness of the prevention program in these organizations to proceed or not the formalization of tax reporting.

\section{Certification prevention model}

Initially, the regulations established that prevention model can be certified by duly registered third parties and accredited, in order to demonstrate compliance with all established elements, however, has subsequently been repealed that provision, from which it follows Regulation could not detail anything about it, because its specific and limited by law character, confined to specify what the law provides and in this case, in the absence anything about it, it should be understood reasonably model prevention does not require certification, the legal person may approve and implement crime prevention program designed ad hoc basis for her by any specialist.

\section{Work in the company criminologist}

The criminologist is a professional who studies the causes, factors, conditions and motives that generate crime. His work is his transcendental because the criminal matter confronts the level of comprehensive security of the state, which is closely linked to the general welfare, as they are interdependent and complementary concepts, which aim to aspiration of social organization all for the common good. Criminological task is also important because it prevents and, in that sense, prevents the occurrence of causes that can lead to behaviours, and conflicting actions which crimes are generated. Avoid reacting by preventing ex post in the conflict, placing ex ante, bringing an advantage, which is the same as that between the actions to clean and not dirty you get. To put it colloquially, a place is cleaner not because more is swept, but because less dirty. In addition, knowing the root causes of harmful behaviours and avoiding them, it is involved in the inter-relationships of interest, where conflict zone, pre- and positive, nor negative extemporaneous not emerge, that is, reacting and punishing. So, who cultivates criminology as a scientific discipline can overcome the use of the criminal justice system to address and overcome crime, can contribute greatly within a legal person, with the same efficiency you can do in the social womb. The difference is that in countries like ours, power is not used criminology criminal justice system but simply to maintain the status quo and continue punishing selective and discriminatory manner. Fortunately, a legal person has certain specific owners and, specifically self-interest, not indirect or indeterminate, the power exercised by these, precisely, does that need to ensure the smooth progress of business or corporate purpose, i.e. your organization do not engage in the commission of crimes, because you are putting their own existence, operations development, economy and prestige. In the business and voluntary sector, other interested anticipate rather than to punish, unlike what happens in the social environment, as the holder of power is the creator, founder, contributor and directly interested in good governance and best business practices. Here then is an enabling collaborative space criminologist with the legal person, not only to avoid criminal responsibility, but to contribute to radiate its social responsibility as being the crime a social phenomenon, and a painful inter personal problem, his avoidance payable social contribution to a company to the community in which it operates. The crux of criminological work is, in the case of program business crime prevention, optimization of all processes that may lead to the use of the organizational structure and operations of the entity in crimes and thus to their involvement and eventually to criminal responsibility. Thus, in addition, the profitability of social rotation is increased by reducing risks of loss and even extinction.

\section{Corporate criminology}

As criminology is an encyclopaedic holistic human and social science, constelacionista, multidisciplinary and is likely to appreciate according to their different fields of application, from which emerge the various criminologist called specific, such as the women criminology, road, urban, development, clinical, psychological, sociological, critical, Children and youth, white, economic neck, among others. In the case of corporate, business or organizational criminology, it is a specialty which aims to handle and manage comprehensive security organizations and their members, through the prevention and control of conditions and factors generating crime that may appear in development or in connection with the activities of the entity. It is glaring, however, that favours teamwork interdisciplinary vision of the subject under study and analysis; so the team in charge of corporate prevention program must be multidisciplinary, depending on the different kinds of activities and operations of the organization. Responsible for directing would have to be a professional who knows and cultivate criminology, to guide the integration of the equipment to the common goal and the successful resolution of 
criminogenic situations. Initially, observation and analysis of the reality of the entity, it must detect and identify vulnerabilities, taking into account all the resources with which the entity operates; then it shall establish the dangers, insecurities and conflicts that may threaten or impact these vulnerabilities. Then it should outline the cons measures and strategies to prevent threats and risks, to design the policies, rules and precautionary procedures, control, inspective, supervisors, information and reporting as well as ethical, motivating and dissuasive. The teleological approach in a program of corporate crime prevention is ensuring the image of the entity, organizational effectiveness, service quality, optimal organizational culture, corporate ethics and social responsibility is founded. That makes it great and enduring to the entity. Obviously, in order to have it and implement it lies in prevention and risk avoidance, whose consummation may eventually end up with the economy of the entity and perhaps its existence. So the message should give a company to own and third is the zero opportunities for your organization to be used for crime. Detect, identify, evaluate and overcome criminogenic risks is the task of the criminologist, always favouring the protection of the interests of the entity in eliminating the danger. It is in this area where the criminologist integrates the various schools and theories that explain the crime risk situations and managing organizational security conditions to ensure the progress and sustainability of the entity. Business, organizational or corporate, criminologist is rising throughout the management process and decision-making, policy, strategy development and generation of shares for safety, with strict adherence to the mission, vision, principles and values of the entity.

\section{Criminal activity and legal person}

It is not until the third decade of the last century criminology focused on the structural aspect, organizational and criminal profile of the legal person, by Edwin Sutherland, who coined the concept of "white collar crime". Neither the criminal law was, as usual, interested in responsible and punish legal persons, but only natural persons, because the concept of subjective responsibility, which requires freedom and will obviously not have the entities to be notional legal subjects. As we have said, criminal law, moreover, is not an appropriate instrument to tackle economic crime, organized transnational or globalized, it does not impact the formation of healthy organizational cultures and in promoting good corporate practices, nor against motivates the individual.

According to criminological experience, it is possible to differentiate a corporate crime a crime of corporate occupation, as committed for the benefit or the benefit of the entity having the entity as a protagonist; or consists of the use of an advantage within the organization by the offending agent, respectively. The list is long and endless, because criminal procedures mutate very dynamically. Limitations and reservations from free trade, such as uniformity and price discrimination and discounts; legal violations on patents, trademarks and copyrights; misleading advertising; unfair labour practices and conditions; financial manipulations; violations of special regulations war; tax evasion; violations of embargoes, for criminological analysis of the corporate culture and organizational structure of the entity must be taken into account because they are always behind the benefit or usefulness present or future and maximum effectiveness at any cost, which makes them potential environments criminogenic. Even if the criminal law has classified criminal organizations, care should be taken to distinguish them from the criminal corporation, for the purpose of those is to commit crimes, for that is up and deplete its reason for being in such illicit activities while this is not, since they have become a lawful purpose, in which precisely fits maximizing revenue and profit, for which can project criminal actions with those specific purposes, such as a better market position, annihilate the competition, create monopolies, among others, where it can be seen that crime is merely a means to achieve their economic goals, which is institutionalized as a business method among the many he owns.

If you attempt to classify the criminogenic organizational policies it could arrive to consider the maximization of economic benefit; the lack of a crime prevention program, which many organizations often translate into fewer rules more operational; and the absence or weakness of an institutional culture of ethical leadership. These policies must be careful, are objectively epidemic because of the theory of differential association the same Edwin Sutherland, precursoramente applied to the Peruvian working environment by Zavala, L. (2016) attorney according to which criminal behaviour is learned, as is also learned virtuous behaviour or activity; learn and interact with others, through a process of communication, which we know occurs regularly and often permanent labour organization. Ergo, if an organizational context which suffers from the above policies, officials with authority and decision-making conduct illegal content deviant behaviour in order to seek the benefit for your organization, encourage or tolerate. In this context longstanding crime and from the regulatory point of view in our country, new to the criminal liability of legal persons, which may lead to its dissolution after passing through the economic downturn, it is imperative to make the inevitable reflection on that if it is appropriate that shareholders, founders, partners, associates, owners, directors, managers, administrators and representatives of legal persons in general and companies in particular postpone further the necessary paradigm shift reaction and hiring criminal lawyers for the prevention and hiring cultists of criminology to lead the multidisciplinary team having responsibility for the vital task of designing, implementing and monitoring a program of crime prevention. We believe it is time to implement the change for the sake of legal persons.

\section{Conclusion}

Criminal activity in a legal person, whatever the cause that originates and the agent who perpetrates from a criminal perspective, should and can be subject to criminal sanction, however, applying a criminological political perspective, should and can be prevention and control. This is the virtue of the introduction in Peru of the new legal obligation for legal persons implement, execute and monitor the proper functioning of a crime prevention program so that they can be exempted from criminal liability. By the nature of the program and the scope of its content, comprising all activities of the organization must be prepared by a multidisciplinary team led by a professional who cultivate criminology, as their cognitive competence in the field will allow direct action interdisciplinary detection and identification of the causes, factors, conditions and criminogenic reasons that constitute the environment in which social organization operations unfold. With the entry into force of the new legal obligation, they doubt that perhaps could have existed in terms of cost-benefit analysis, regarding what is best for the company or legal person defend himself against a criminal charge hiring a criminal lawyer for a particular case fade, to hire all the ad hoc advance development of a prevention program and monitor its 
proper operation, performed by a professional culture of criminology. Complete this analysis which makes insurance purposes, it's better to have it and not need it, than to need it and not have it, since it is a mechanism for exemption from criminal responsibility and not merely a guarantee of financial payment from a third party (the insurer) if the risk occurs. We have already seen today, legal persons in general and businesses in particular are subject to a permanent state of risk, danger and compromise safety due to the vertiginous dynamics of operations and the frenetic activity of economic actors, permanently motivated by maximizing profits at any cost. To that extent, it is challenging for corporate criminology this latest legal obligation because, according to the circumstances of modern life, besieging natural persons, who create and / or make legal persons, constitutes an invaluable opportunity to meet, this state of necessity, the importance and significance of criminology as a scientific discipline that goes beyond criminal law in building effective policies and strategies to control the criminal matter, which in the world of legal organizations are all the more essential as its lack entails serious economic and moral involvement, if not the disappearance of the entity.

\section{Conflict of interest}

The author declares that there is no conflict of interest.

\section{References}

1. Zaffaroni Raul Eugenio. Delegitimization and dogmatic criminal justice. Buenos Aires: EDIAR, 1998.

2. Borja Emiliano. Criminal Policy Course, Valencia: Tirant lo Blanch. 2003.

3. Pérez Alvaro. Criminology Course, 2nd edition, Bogotá. Themis. 1986.

4. Tonkonoff Sergio. The social functions of crime and punishment. $A$ comparison between the perspectives of Durkheim and Foucault "in Sociological, Mexico City. 2012; 27(77):109-142.

5. Ten Joseph. The symbolic criminal law and the effects of punishment. Mexican Comparative Law Bulletin. 2002;35(103):409-447.

6. Zavala, Lizet. "Labor Criminology," Criminology. Multidisciplinary approaches. Gino Rios Patio, USMP, Lima: Publishing Fund of the USMP, 2016

\section{Acknowledgements}

None 